\title{
CARDIOPROTECTIVE EFFECT OF DATE PALM AGAINST DOXORUBICIN-INDUCED CARDIOTOXICITY
}

\author{
SHIMAA MUBARAK ${ }^{1 *}$, SHADIA ABDEL HAMID ${ }^{1}$, ABDEL RAZIK FARRAG ${ }^{2}$, NAHLA SAMIR ${ }^{1}$, JIHAN SEID HUSSEIN ${ }^{3}$ \\ ${ }^{1}$ Department of Biochemistry, Faculty of Science, Ain Shams University, Cairo, Egypt. ${ }^{2}$ Department of Pathology, National Research Centre \\ Cairo, Egypt. ${ }^{3}$ Department of Medical Biochemistry, National Research Centre, Cairo, Egypt. Email: Shimaamubarak2015@yahoo.com
}

Received: 28 December 2017, Revised and Accepted: 30 March 2018

\section{ABSTRACT}

Objective: Doxorubicin (Dox), an anthracycline antibiotic, has been widely used to treat cancer, principally hematological malignancies, and solid tumors. The administration of Dox is a topic of concern in the medical community, as it frequently related to dose-dependent cardiotoxicity. Therefore, the present study was designed to investigate the protective potential of date palm fruit extract on Dox-induced cardiotoxicity.

Methods: A total of 40 female albino rats were used in this study and classified into four groups including control, date palm fruit extract, Dox, and treated date palm fruit extract groups.

Results: Dox produced a significant increase in creatine kinase-MB and lactate dehydrogenase activities. It also decreased the activities of cardiac glutathione peroxidase and superoxide dismutase but increase levels of cardiac malondialdehyde and also of urinary 8-hydroxy-2-deoxyguanosine. Myocardial toxicity of Dox also appeared in the elevation of serum total cholesterol, triglycerides, and low-density lipoprotein cholesterol levels, while level of high-density lipoprotein cholesterol decreased. Histopathological studies revealed alteration of cardiac tissue structure by Dox. Treatment with date palm fruit extract restored the aforementioned parameters.

Conclusion: Date palm fruit exhibits a cardioprotective influence on the heart tissue against toxicity induced by Dox.

Keywords: Phoenix dactylifera L., Cardioprotective, Doxorubicin, Cardiotoxicity, 8-hydroxy-2-deoxyguanosine, High-performance liquid chromatography.

(C) 2018 The Authors. Published by Innovare Academic Sciences Pvt Ltd. This is an open access article under the CC BY license (http://creativecommons. org/licenses/by/4. 0/) DOI: http://dx.doi.org/10.22159/ajpcr.2018.v11i7.24453

\section{INTRODUCTION}

In parallel with the increase in the number of confirmed cases of cancer, new modalities of treatment have increased cancer survival and possibilities of cure. However, the treatment may cause several adverse effects including treatment-related cardiotoxicity that may lead to poorer prognosis than cancer itself, and also affect treatment continuation [1,2].

Patients with malignant neoplasm may have underlying cardiovascular diseases, the consequences of which are often exacerbated by the tumor growth stress or its treatment. With the start of new treatments and consequent extended survival time, late effects of cancer treatment can become clinically manifest decades after completion of therapy. The heart's extensive energy reserve and its ability to compensate for reduced function increase the complexity of diagnosis and initiation of therapy. Treatment-related impairment of cardiac contractility may be reversible or irreversible. In addition, the treatment of cancer is well associated with life-threatening arrhythmia, infarction, ischemia, and damage to the conduction system and cardiac valves. Knowledge of these processes has gained importance to give us an idea about strategies to prevent and monitor cardiovascular damage [3].

The principle for the study of how cancer and/or its treatment could affect the heart resulting from the observations that anthracyclines caused progressive heart failure which is dose-dependent and may cause cardiac death $[3,4]$.

Antitumor anthracyclines such as doxorubicin (Dox), idarubicin, daunorubicin, and epirubicin are broadly used to treat hematologic malignancies and solid tumors; on the other hand, the clinical apply of anthracyclines is very limited due to their severe cardiotoxicity, which correlates with the cumulative administered dose $[5,6]$.
It has been found that Dox stimulates free radicals that cause cell damage through entering into cardiomyocytes by passive diffusion. In addition, Dox inhibits gene transcription, mitochondrial function, and energy production by direct or indirect mechanisms $[7,8]$.

Cardiotoxicity is responsible for free radicals production, enzymatic and non-enzymatic pathways, and redox-related damage caused by iron accumulation. In addition, it has been suggested that negative disturbance of the balance between antioxidant systems and free radicals is the main factor of cardiotoxicity [9].

In this respect, two pathways proposed for free radical generation by Dox [10]; the first mechanism is that Dox accepts an electron generated in the reaction catalyzed by flavoprotein enzymes and is converted to a reactive semiquinone form, which then spontaneously reacts with molecular oxygen producing a superoxide anion. The second mechanism is the non-enzymatic formation of a Dox- $\mathrm{Fe}^{2+}$ free radical complex, which then reacts with hydrogen peroxide $\left(\mathrm{H}_{2} \mathrm{O}_{2}\right)$ resulting in hydroxyl radicals formation. These reactive oxygen species (ROS) react with proteins, nucleic acids, lipids, and other cellular constituents causing diverse oxidative damage to the cell membrane and mitochondria in heart muscle cells [11-13].

Date palm tree (Phoenix dactylifera L.) is well thought out as one of the main ancient and staple crops in North Africa and Southwest Asia. Moreover, dates grown in Southern Africa, Australia, South America, Mexico, and the United States, especially in Southern California, Texas, and Arizona [14,15].

Date palm fruit has been reported to be a good source of high nutritional value food. In fact, it is rich in carbohydrates, proteins, dietary fibers, minerals, and vitamin B complex, such as thiamine (B1), riboflavin 
(B2), niacin (B3), pantothenic (B5), pyridoxine (B6), and folate (B9) [16]. Besides, it regarded as a good source of antioxidant vitamins $\mathrm{A}, \mathrm{C}$, and $\mathrm{E}$. The anthocyanins, isoquercetrin, quercetin, quercetrin, procyanidins, apigenin, luteolin, and rutin constitute the flavonoid content of date palm fruit [17].

Numerous studies that have been conducted in the past four decades proposed that date palm fruits have varied medical apply such as anti-inflammatory, antihyperlipidemic, anticancer, gastroprotective, hepatoprotective, and nephroprotective activities and thus serving as a vital healthy food in the human diet [18].

In accordance with the aforementioned medicinal properties of date palm fruit, the present research has been designed to investigate the protective potential of date palm fruit extract against cardiotoxic effect of Dox drug.

\section{MATERIALS AND METHODS}

\section{Chemicals}

Oncodox - 50 mg vial (Doxorubicin hydrochloride USP, Mfd. by CIPLA LTD., INDIA) was purchased from local pharmacy. 8-hydroxyguanosine standard (high-performance liquid chromatography [HPLC] grade) was purchased from Sigma-Aldrich Company, ST. Louis, MO, USA.

\section{Plants}

Date fruits (P. dactylifera L. Palmae) Zaghlool were purchased from local market, Egypt.

\section{Experimental animals}

Female albino rats (Laboratory Animal Colony, National Research Centre, Cairo, Egypt) weighing 120-140 g were used in this study. Animals were housed in stainless steel community cages at $25 \pm 2^{\circ} \mathrm{C}, 12 \mathrm{~h}$ light/ dark cycle and allowed to acclimatize for 7 days before experimental use. Throughout the experiment, the rats were allowed free access feed (rats dietary pellets prepared by Cairo Company of Oil and Soap, Egypt) and water. The experiment was carried out in accordance with the Research Ethics Committee for Animal Subject Research at National Hepatology \& Tropical Medicine Research Institute (NHTMRI - IRB) Cairo, Egypt.(serial:10-2018).

\section{Plant extraction}

About $500 \mathrm{~g}$ of edible portion of date fruits have been cutted into small pieces and extracted with $1 \mathrm{~L}$ of aqueous methanol (70\%) by soaking for about 4 days at room temperature. The alcoholic extract was concentrated under reduced pressure using rotaevaporator (Heidolph, Hei-VAP series, GmbH and Co. KG in Schwabach, Germany). The used dose was ( $4 \mathrm{ml} / \mathrm{kg}$ b.w.) according to Vayalil [19].

\section{Induction of cardiotoxicity}

Dox was dissolved in $0.9 \%$ saline immediately before use, protected from light and given intraperitoneally (I.P) at a dose of $15 \mathrm{mg} / \mathrm{kg}$ b.w. before $48 \mathrm{~h}$ of blood sampling according to Chabner et al. [20].

\section{Experimental design}

A total of 40 female albino rats were used and divided into four groups (10 rats in each group) as follows:

Group I (control group): Healthy rats served as control group and received a vehicle.

Group II (date group): Healthy rats received date palm fruit extract (4 ml/kg b.w./day orally) for 30 days [19].

Group III (Dox group): Healthy rats received a vehicle and then received a single dose of Dox (15 mg/kg b.w., i.p.) at the end of experimental period $[20]$.

Group IV (treated group): Healthy rats received date palm fruit extract ( $4 \mathrm{ml} / \mathrm{kg}$ b.w./day orally) for 30 days and then received a single dose of
Dox (15 mg/kg b.w., i.p.).

At the end of the experimental period (30 days), animals were kept in metabolic individual cages for collection of $24 \mathrm{~h}$ urine samples for estimation of urinary 8-hydroxyguanosine.

\section{Blood sampling}

After the experimental period, rats were anesthetized using diethyl ether by inhalation then fasting blood samples were withdrawn from the retro-orbital venous plexus of the eye using capillary tubes, according to the method of Madway et al. [21]. Blood samples were collected in dry tube, left to clot, and serum was separated by centrifugation at $3000 \mathrm{rpm}$ using cooling centrifuge (Laborzentrifuge, 2K15, Sigma, Germany) for $15 \mathrm{~min}$; samples were divided into aliquots and stored at $-20^{\circ} \mathrm{C}$ for biochemical assays.

After blood samples were obtained, rats were decapitated, and heart tissues were separated and prepared for histopathological examination by routine light microscopic methods.

\section{Preparation of tissue homogenate}

Heart tissues were cutted into small pieces and homogenized in $5 \mathrm{ml}$ cold buffer $\left(0.5 \mathrm{~g}\right.$ of $\mathrm{Na}_{2} \mathrm{HPO}_{4}$ and $0.7 \mathrm{~g}$ of $\mathrm{NaH}_{2} \mathrm{PO}_{4}$ per $500 \mathrm{ml}$ deionized water [pH 7.4]) per g tissue, then centrifuged at $4000 \mathrm{rpm}$ for $15 \mathrm{~min}$ at $4^{\circ} \mathrm{C}$. Supernatant was then separated and used for estimation of oxidant/antioxidant parameters [22].

\section{Biochemical assays \\ Biochemical markers of cardiotoxicity}

Serum creatine kinase-MB (CK-MB) and lactate dehydrogenase (LDH) activities were determined using automated cobas c 311 system (Roche Diagnostics, Mannheim, Germany)

\section{Lipid profile}

Serum triglycerides (TGs) were determined by glycerol-phosphateoxidase method as described by Jacobs and Vandemark [23]. Serum total cholesterol (TC) was determined using enzymatic method of Allain et al. [24]. Serum high-density lipoprotein cholesterol (HDL-C) was determined according to the method described by Fruchart et al. [25]. Dependently low-density lipoprotein cholesterol (LDL-C) was calculated by the Friedewald formula [26]

\section{Oxidant and antioxidant profile}

Cardiac glutathione peroxidase (GPx) and superoxide dismutase (SOD) activities were assayed by the method of Pagalia and Valentine [27] and Nishikimi et al. [28], respectively. Cardiac malondialdehyde (MDA) was determined according to Ohkawa et al. [29].

\section{Determination of urinary 8-hydroxy-2-deoxyguanosine (8-OHdG)} using HPLC

8-OHdG was estimated by HPLC system, Agilent technologies 1100 series, equipped with a quaternary pump (Quat Pump, G131A model) according to Kim et al. [30] modified by Hussein et al. [31].

\section{Standard preparation}

For stock preparation, $1 \mathrm{mg}$ standard was dissolved in $1 \mathrm{ml}$ ultrapure water, and several dilutions were prepared, $20 \mu$ from serial dilutions of standard was injected onto HPLC to draw a standard curve with different concentrations.

\section{Sample extraction}

8-OHdG was extracted from $1 \mathrm{ml}$ urine. The eluents were dried under $\mathrm{N}_{2}$ stream, reconstituted in $5 \mathrm{ml}$ ultrapure water, and filtered by PVDF $0.45 \mu \mathrm{m}$ filter. $20 \mu \mathrm{l}$ from each sample was injected onto HPLC.

\section{HPLC condition}

The mobile phase was consisted of acetonitrile/methanol/phosphate 
buffer $(25 / 10 / 965) \mathrm{v} / \mathrm{v}$, respectively. Phosphate buffer was prepared by dissolving $8.8 \mathrm{~g}$ of potassium dihydrogen phosphate in $1000 \mathrm{ml}$ ultrapure water and $\mathrm{pH}$ was adjusted at 3.0; the buffer was then filtered 2 times through sterile membrane filters $(47 \mathrm{~mm}$ Diam, pore size $0.45 \mu \mathrm{m}$ ) before being used at a flow rate of $1 \mathrm{ml} / \mathrm{min}$ through C18 column $(250 \times 4.6$, particle size $5 \mu \mathrm{m})$ using electrochemical detector with cell potential of $600 \mathrm{mV}$.

\section{Calculation}

The concentration of urinary 8-OHdG was calculated from the standard curve and divided on the urinary creatinine. Urinary creatinine was estimated by kinetic method as described by Larsen [32].

\section{Histopathological examination of heart}

Heart tissue was obtained from all experimental groups, washed immediately with saline and then fixed in $10 \%$ buffered neutral formalin solution. After fixation, the heart tissue processed by embedding in paraffin. Then, the heart tissue sectioned and stained with hematoxylin and eosin and examined under high power microscope $(100 \times)$ [33].

\section{Statistical analysis}

All results were expressed as mean \pm standard error; data were analyzed by one-way analysis of variance [34] by means of SPSS statistical software (version 17) followed by LSD test to compare significance between groups. Difference was considered statistically significant when $\mathrm{p} \leq 0.05$.

\section{RESULTS AND DISCUSSION}

Dox, a member of anthracycline antibiotic class, is recognized as one of the most effective and widely used chemotherapeutic therapy for the treatment of a wide range of human cancers. However, clinical use of Dox is severely limited due to its significant cardiotoxic effects, which frequently resulting in the development of irreversible degenerative cardiomyopathy and ultimately heart failure $[35,36]$.

Although numerous mechanisms have been proposed, most studies supported the increase in oxidative stress, along with reductions in the levels of antioxidants, which play a key role in the pathogenesis of Dox-induced cardiomyopathy. Consequently, the addition of natural or synthetic antioxidants to anticancer therapy may guard against the oxidative stress induced by Dox and other cytotoxic drugs [37]. Fruits and vegetables have been associated with decreased risks of several chronic diseases, involving oxidative stress and inflammation [38]

Date palm is one of the ancient trees cultivated from 6000 years. The

Table 1: CK-MB and LDH in different studied groups

\begin{tabular}{|c|c|c|}
\hline Groups & CK-MB (U/l) & LDH (U/l) \\
\hline \multicolumn{3}{|l|}{ Control } \\
\hline Mean $\pm S E$ & $568 \pm 39.0$ & $992 \pm 37.2$ \\
\hline \multicolumn{3}{|l|}{ Date } \\
\hline Mean $\pm S E$ & $505 \pm 23.4^{\mathrm{b}}$ & $900.8 \pm 31.6^{b}$ \\
\hline$\%$ change $^{a}$ & $-11.1 \%$ & $-2.3 \%$ \\
\hline$\%$ change $^{\mathrm{b}}$ & $-34.3 \%$ & $-28.1 \%$ \\
\hline \multicolumn{3}{|l|}{ Dox } \\
\hline Mean \pm SE & $769 \pm 42.7^{\mathrm{a}}$ & $1253 \pm 30.4^{\mathrm{a}}$ \\
\hline$\%$ change $^{a}$ & $35.3 \%$ & $35.9 \%$ \\
\hline \multicolumn{3}{|l|}{ Treated } \\
\hline Mean $\pm S E$ & $657 \pm 47^{b}$ & $911 \pm 38^{b}$ \\
\hline$\%$ change $^{\mathrm{a}}$ & $15.6 \%$ & $-1.2 \%$ \\
\hline$\%$ change $^{\mathrm{b}}$ & $-14.5 \%$ & $-27.3 \%$ \\
\hline \multicolumn{3}{|c|}{ 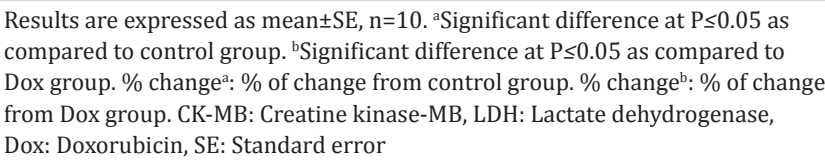 } \\
\hline
\end{tabular}

different parts of date palm fruit are commonly used in traditional medicine to treat various disorders [18,39].

It has been demonstrated by several phytochemical studies that date palm fruits contain anthocyanins, sterols, carotenoids, phenolics, and procyanidins compounds which contribute to the numerous biological effects of date palm fruit as free radical scavenging, antioxidant, antimicrobial, antimutagenic, and immunostimulant activities $[18,40]$.

The present work has been planned to explore the ability of date palm fruit extract in protection against cardiotoxicity induced by Dox in rats.

Cardiotoxicity induced by Dox is due to destruction of myocardial cells. This can lead to leakage of CK-MB and LDH into the circulation and serve as the diagnostic markers of myocardial injury. Therefore, the alteration in plasma membrane integrity and/or permeability is reflected by amount of these cellular enzymes in the bloodstream [41,42].

In this study, we observed that Dox treatment resulted in significant increase in both serum cardiac enzymes LDH and CK-MB activities. These results are in agreement with those reported by Argun et al. [8] and QuanJun et al. [43]. Whereas, the treatment by date palm fruit extract significantly decreases the mean values of serum CK-MB and LDH in compared to Dox group indicating its strong cardioprotective efficacy against Dox toxicity (Table 1).

El Arem et al. [44] reported that administration of date palm fruit extract restored the hepatic damage stimulated by trichloroacetic acid as confirmed by amelioration of LDH activity. Findings of the research by Abdalla et al. [40] reveal that treatment with dietary dates significantly reduced the increased activities of CK-MB and LDH. In a study performed by Daoud et al. [45], to evaluate the protective effect of date palm pollen (DPP) ethanolic extract on isoproterenol-induced myocardial infarction, pre-co-treatment with DPP extract enhanced the cardiac biomarkers injury, creatine phosphokinase, alanine aminotransferase, $\mathrm{LDH}$, and troponin-T.

Administration of Dox to rats significantly increases the levels of serum TC, TG, and LDL-C but significantly decreases serum level of HDL-C compared to control (Table 2). These results were coincided with Dhana et al. [46] and Mansouri et al. [47].

These variations in the profile of lipid show that there is a possible interference of Dox with metabolism or biosynthesis of lipids $[48,49]$. Dox administration may lower the level of cytochrome $P 450$ which then depresses activity of cholesterol 7-hydroxylase, the enzyme responsible for the conversion of cholesterol to bile acids [50].

The results revealed that consumption of date palm fruit exerts a lipidlowering effect by inducing a significant decrease in serum levels of TC and LDL-C but insignificantly decrease serum level of TG. Even as there was insignificant increase in serum HDL-C compared to Dox group (Table 2).

These findings were in agreement with previous studies of Alsaif et al. [51] and Hasan et al. [52] who reported that the supplementation with date palm fruit reduced the concentrations of TC, TG, and LDL-C while caused elevation in levels of HDL-C in hypercholesterolemic hamsters and rabbit, respectively. In addition, date palm fruit extract treatment improved the changes in lipid profile in mice infected with the Eimeria papillata [53].

Dox and other antitumor anthracyclines have a tetracyclic quinonehydroquinone moiety, an aminosugar (daunosamine) and a short side chain with a carbonyl group. The quinone moiety is converted into a semiquinone radical by reduction of one electron. The parent quinone is then rapidly regenerated by reduction of molecular oxygen to superoxide anion and then dismutation of the latter produce $\mathrm{H}_{2} \mathrm{O}_{2}$. Therefore, the persistent redox cycling of the quinone moiety exposes 
Table 2: Lipid profile in different studied groups

\begin{tabular}{|c|c|c|c|c|}
\hline Groups & Total cholesterol (mg/dl) & Triglycerides (mg/dl) & HDL (mg/dl) & LDL (mg/dl) \\
\hline \multicolumn{5}{|l|}{ Control } \\
\hline Mean \pm SE & $85 \pm 2.27$ & $71.3 \pm 2.63$ & $38.8 \pm 0.85$ & $31.5 \pm 2.7$ \\
\hline \multicolumn{5}{|l|}{ Date } \\
\hline Mean \pm SE & $89.6 \pm 4.56^{b}$ & $69 \pm 2.61^{b}$ & $40.78 \pm 1.0^{\mathrm{b}}$ & $36.8 \pm 3.7^{b}$ \\
\hline$\%$ change $^{a}$ & $5.4 \%$ & $-3.2 \%$ & $5.1 \%$ & $16.8 \%$ \\
\hline$\%$ change $^{\mathrm{b}}$ & $-18 \%$ & $-26 \%$ & $25.2 \%$ & $-41.4 \%$ \\
\hline \multicolumn{5}{|l|}{ Dox } \\
\hline$\%$ change $^{a}$ & $30 \%$ & $30.8 \%$ & $-16.2 \%$ & $99.3 \%$ \\
\hline \multicolumn{5}{|l|}{ Treated } \\
\hline Mean \pm SE & $99.5 \pm 3.51^{\mathrm{a}, \mathrm{b}}$ & $85.5 \pm 3.62^{\mathrm{a}}$ & $36.2 \pm 2.0$ & $44.7 \pm 4.6^{\mathrm{a}, \mathrm{b}}$ \\
\hline$\%$ change $^{a}$ & $17 \%$ & $19.9 \%$ & $-6.7 \%$ & $41.9 \%$ \\
\hline$\%$ change $^{\mathrm{b}}$ & $-10 \%$ & $-8.36 \%$ & $11.4 \%$ & $-28.8 \%$ \\
\hline
\end{tabular}

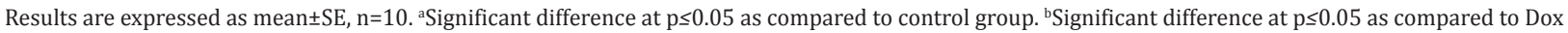
group. \% change ${ }^{\mathrm{a}}$ : \% of change from control group. \% change ${ }^{\mathrm{b}}$ \% \% of change from Dox group. Dox: Doxorubicin, SE: Standard error, HDL: High-density lipoprotein LDL: Low-density lipoprotein

Table 3: Oxidant/antioxidant parameters in different studied groups

\begin{tabular}{|c|c|c|c|c|}
\hline Groups & GPx (U/g tissue) & SOD (U/g tissue) & MDA (nmol/g tissue) & 8-0HdG (ng/mg creatinine) \\
\hline \multicolumn{5}{|l|}{ Control } \\
\hline Mean \pm SE & $4.2 \pm 0.5$ & $303.3 \pm 5.4$ & $30.8 \pm 7.5$ & $5.1 \pm 0.17$ \\
\hline \multicolumn{5}{|l|}{ Date } \\
\hline Mean \pm SE & $4.7 \pm 1.0^{\mathrm{b}}$ & $315.17 \pm 3.5^{b}$ & $21.1 \pm 3.8^{b}$ & $4.9 \pm 0.12^{\mathrm{b}}$ \\
\hline$\%$ change $^{a}$ & $11.9 \%$ & $4.09 \%$ & $-31.5 \%$ & $-2.7 \%$ \\
\hline$\%$ change $^{b}$ & $90 \%$ & $13.44 \%$ & $-47.5 \%$ & $-46 \%$ \\
\hline \multicolumn{5}{|l|}{ Dox } \\
\hline Mean \pm SE & $2.47 \pm 0.23$ & $278.2 \pm 8.9^{\mathrm{a}}$ & $40.2 \pm 6.4$ & $9.2 \pm 0.29^{\mathrm{a}}$ \\
\hline$\%$ change $^{a}$ & $-41.2 \%$ & $-8.2 \%$ & $30.5 \%$ & $80.4 \%$ \\
\hline \multicolumn{5}{|l|}{ Treated } \\
\hline Mean \pm SE & $3.6 \pm 0.5$ & $299.17 \pm 6.6^{\mathrm{b}}$ & $32.0 \pm 3.5$ & $6.1 \pm 0.12^{\mathrm{a}, \mathrm{b}}$ \\
\hline$\%$ change $^{a}$ & $-14.3 \%$ & $-1.36 \%$ & $3.9 \%$ & $19.6 \%$ \\
\hline$\%$ change $^{\mathrm{b}}$ & $45.7 \%$ & $7.5 \%$ & $-20.4 \%$ & $-33.7 \%$ \\
\hline
\end{tabular}

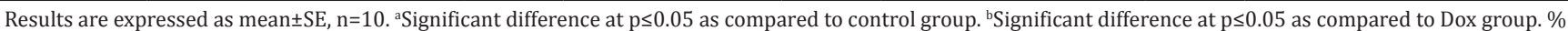
change ${ }^{\mathrm{a}}$ \% of change from control group. \% change $\%$ of change from Dox group. Dox: Doxorubicin, SE: Standard error, GPx: Glutathione peroxidase, SOD: Superoxide dismutase, MDA: Malondialdehyde, 8-OHdG: 8-hydroxy-2-deoxyguanosine

cardiomyocytes to ROS that, in concert with iron, may lead to oxidative stress [6].

ROS can receive electrons from the lipids in cell membranes, resulting in lipid peroxidation which contributes to oxidant-induced cell death. MDA, a major and constant final product of peroxidation, is known as a commonly marker of lipid peroxidation [54]. Besides, ROS can cause structural and functional damage of mitochondria, which may result in cardiomyocytes apoptosis or death [55].

Cells have evolved different antioxidants to neutralize ROS which can suppress lipid peroxidation; so they are extremely vital for inhibiting oxidative stress-induced cytotoxicity. Antioxidant enzymes such as SOD, GPx, and catalase are capable of inhibiting the oxidation so that they are the major intracellular antioxidant defenses system. Consequently, overexpression of antioxidant enzymes can provide protective effects against the cardiomyocytes damage induced by ROS [56].

The reduction in myocardial antioxidant enzyme (SOD and GPx) activities in Dox group has been observed in this study. In addition, cardiotoxicity was further confirmed by increase in the cardiac MDA concentrations compared to the control group (Table 3). These results are consistent with the previous study reported by Chen et al. [57]. While date palm fruit extract, administration restored the cardiotoxicity induced by Dox as showed by amelioration of cardiac SOD, GPx activities, and cardiac MDA level.
These results were in agreement with Saafi et al. [58] who studied the hepatoprotective effect of date palm fruit extract on dimethoate-induced oxidative stress, and also with El-Gazzar et al. [59] who reported that pretreatment with Siwa date palm fruit extract ameliorated the elevation in hepatic MDA level induced by carbon tetrachloride $\left(\mathrm{CCL}_{4}\right)$. In addition, activity of SOD increased toward the normal value by administration of hydromethanolic extract of date palm fruit in $\mathrm{CCL}_{4}$-intoxicated rats [60].

Feeding animals with dietary date palm fruit have been found to decrease the level of cardiac MDA and induce an enhancement in cardiac SOD and glutathione activities in a study by Abdalla et al. [40] planned to assess cardiac remodeling by dietary dates in Dox-intoxicated rats.

Under normal conditions, the free radicals attack nuclear and mitochondrial deoxyribonucleic acid (DNA), causing mutagenic DNA lesions; one of these lesions is $8-\mathrm{OHdG}$, which is the end product of guanine hydroxylation. The DNA lesions are, hence, removed by the base excision repair (BER) pathway, which prevents DNA lesions replication. However, ROS can inhibit BER which may potentiate mutagenesis and DNA damage [61,62].

Increased levels of 8-OHdG, an indicator of oxidative DNA damage, have been indicated in a variety of pathophysiological processes such as aging, carcinogenesis, degenerative and cardiovascular diseases [63,64], liver injury [65], and diabetes [31]. It has been reported that Dox able to generate $8-0 \mathrm{HdG}$ in human promyelocytic leukemia cells and MCF-7 breast cancer cells $[66,67]$. 


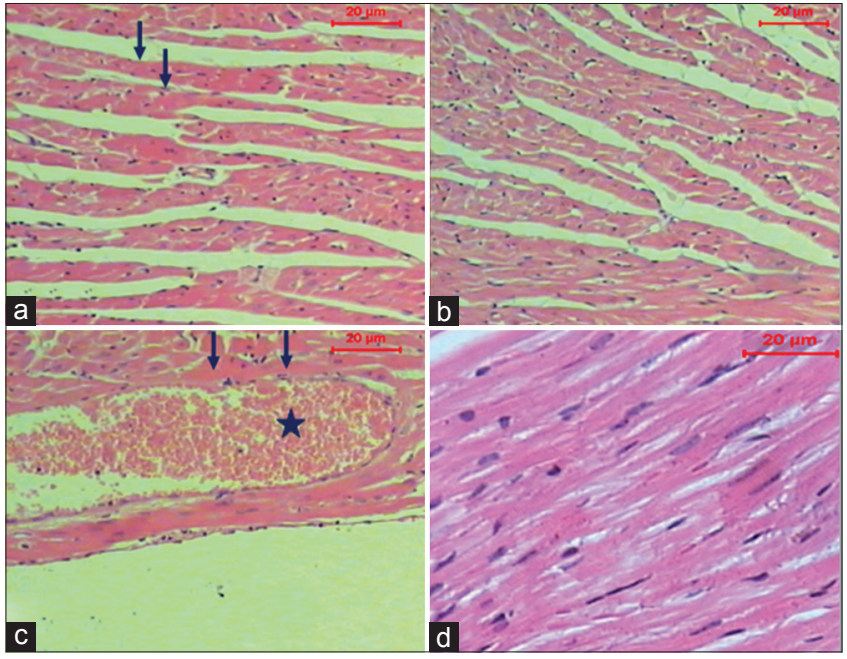

Figure 1: A micrograph of a section from myocardial tissue of

(a) control rat showing normal cardiac muscle (arrows), (b) date palm group showing normal cardiac muscle, (c) Dox group showing interstitial edema between irregular wavy-directed cardiomyocytes (arrows), interfibrillar congestion (asterisk), mild inflammatory cellular infiltration and fibrosis (arrowhead), and myofibrolysis, (d) treated group showing myocardial that appeared more or less like control group (H and E, Scale bar: $20 \mu \mathrm{m}$ )

It has been observed in the present investigation that administration of Dox to rats significantly increase levels of urinary 8-OHdG.While pretreatment with date palm fruit extract has been shown to significantly decrease levels of urinary 8-OHdG.

Histological examination of sections from control group illustrated normal characteristic features of myocardium with no cellular infiltration and normal vasculature. Myocardium is striated with branching, and the nucleus is located centrally. Occasionally, myocardium is binucleated. Intercalated discs between cardiac cells are seen (Fig. 1a). Normal myocardial features similar to that of normal control group were shown in date palm fruit group (Fig. 1b).

In this investigation, typical histopathological alterations such as interstitial edema between irregular wavy-directed cardiomyocytes, vascular dilatation and congestion, mild inflammatory cellular infiltration and fibrosis and myofibrolysis have been observed following Dox administration (Fig. 1c). This coincided with the work of the previous studies $[68,69]$.

Quanjun et al. [43] found that Dox treatment resulted in chronic focal inflammatory pathology in the myocardium. This inflammatory infiltrate reflects the replacement of degenerated myocardial muscle fibers with plasma cells and lymphocytes.

In contrast, microscopic examination of sections from the heart of date palm fruit extract treated rats showed myocardial that appeared more or less like normal one (Fig. 1d). The histopathological examinations of a study by Abdalla et al. [40] showed that the distorted architecture of the cardiomyocytes induced by Dox has been restored by feeding animals with the dietary date palm fruits.

\section{CONCLUSION}

Date palm fruit extract administration protects against Dox-induced myocardial toxicity by reducing cardiac injury markers, reestablishment of oxidant/antioxidant parameters, ameliorating lipid profile, and lessening the histopathological changes. These effects may be due to its high contents of flavonoid (anthocyanins, apigenin, isoquercetrin, quercetin, quercitrin, procyanidins, luteolin, and rutin) and its lipid lowering effects.

\section{ACKNOWLEDGMENTS}

The authors are thankful to the National Research Centre (NRC) for unlimited help and support to carry out this work.

\section{CONFLICTS OF INTEREST}

The present study was performed in the absence of any conflicts of interest.

\section{REFERENCES}

1. Hayward R, Lyen CY, Jensen BT, Hydock DS, Schneider CM. Exercise training mitigates anthracycline-induced chronic cardiotoxicity in a juvenile rat model. Pediatr Blood Cancer 2012;59:149-54

2. Maia TN, Araujo GB, Teixeira JA, Alves ED Jr., Dias KP. Cardiotoxicity of doxorubicin treatment and physical activity: A systematic review. Int J Cardiovasc Sci 2017;30:70-80.

3. Ewer MS, Ewer SM. Cardiotoxicity of anticancer treatments. Nat Rev Cardiol 2015;12:547-58.

4. Henson KE, McGale P, Taylor C, Darby SC. Radiation-related mortality from heart disease and lung cancer more than 20 years after radiotherapy for breast cancer. Br J Cancer 2013;108:179-82.

5. Salvatorelli E, Menna P, Cantalupo E, Chello M, Covino E, Wolf FI, et al. The concomitant management of cancer therapy and cardiac therapy. Biochim Biophys Acta 2015;1848:2727-37.

6. Menna P, Salvatorelli E. Primary prevention strategies for anthracycline cardiotoxicity: A Brief overview. Chemotherapy 2017;62:159-68.

7. Harake D, Franco VI, Henkel JM, Miller TL, Lipshultz SE. Cardiotoxicity in childhood cancer survivors: Strategies for prevention and management. Future Cardiol 2012;8:647-70.

8. Argun M, Uzüm K, Sonmez MF, Ozyurt A, Karabulut D, Soyersarıca Z, et al. Cardioprotective effect of metformin against doxorubicin cardiotoxicity in rats. Anatol J Cardiol 2016;16:234-41.

9. Tocchetti CG, Carpi A, Coppola C, Quintavalle C, Rea D, Campesan M, et al. Ranolazine protects from doxorubicin-induced oxidative stress and cardiac dysfunction. Eur J Heart Fail 2014;16:358-66.

10. Mukhopadhyay P, Rajesh M, Bátkai S, Kashiwaya Y, Haskó G, Liaudet L, et al. Role of superoxide, nitric oxide, and peroxynitrite in doxorubicin-induced cell death in vivo and in vitro. Am J Physiol Heart Circ Physiol 2009;296:H1466-83.

11. Singal PK, Li T, Kumar D, Danelisen I, Iliskovic N. Adriamycininduced heart failure: Mechanisms and modulation. Mol Cell Biochem 2000;207:77-86.

12. Chitra V, Bhagyasri DK, Lokesh AG, Rajalakshmi V. Pharmacodynamic interaction of aqueous extract of garlic with atorvastatin in doxorubicininduced cardiotoxicity in rats. Int J Pharm Pharm Sci 2013;5:440-9.

13. Zhang M, Ma J, Bi H, Song J, Yang H, Xia Z, et al. Characterization and cardioprotective activity of anthocyanins from Nitraria tangutorum bobr. By-products. Food Funct 2017;8:2771-82.

14. Hazzouri KM, Flowers JM, Visser HJ, Khierallah HS, Rosas U, Pham GM, et al. Whole genome re-sequencing of date palms yields insights into diversification of a fruit tree crop. Nat Commun 2015;6:8824.

15. Al-Alawi RA, Al-Mashiqri JH, Al-Nadabi JSM, Al-Shihi BI, Baqi Y. Date palm tree (Phoenix dactylifera L.): Natural products and therapeutic options. Front Plant Sci 2017;8:845

16. Al-Harrasi A, Rehman NU, Hussain J, Khan AL, Al-Rawahi A, Gilani SA, et al. Nutritional assessment and antioxidant analysis of 22 date palm (Phoenix dactylifera) varieties growing in sultanate of Oman. Asian Pac J Trop Med 2014;7S1:S591-8.

17. El-Far AH, Shaheen HM, Abdel-Daim MM, Al Jaouni SK, Mousa SA. Date palm (Phoenix dactylifera): Protection and remedy food. Curr Trends Nutraceuticals 2016;1:2-9.

18. Baliga MS, Baliga BR, Kandathil SM, Bhat HP, Vayalil PK. A review of the chemistry and pharmacology of the date fruits (Phoenix dactylifera L.). Food Res Int 2011;44:1812-22.

19. Vayalil PK. Antioxidant and antimutagenic properties of aqueous extract of date fruit (Phoenix dactylifera L. Arecaceae). J Agric Food Chem 2002;50:610-7.

20. Chabner BA, Ryan DP, Paz-Ares L, Garcia-Carbonevo R, Calabresi P. Antineoplastic agents. In: Hardman JG, Limbird LE, Gilman AG, editors. Goodman and Gilman's the Parmacological Basis of Therapeutics. USA: McGraw-Hill Companies Inc.; 2001. p. 1389-459.

21. Madway W, Prier LE, Wilkinson JS. A Textbook of Veterinary Clinical Pathology. Battimore: The Willims and Wilking Co.; 1969.

22. Hussein J, Abo El-matty D, El-Khayat Z, Abdel-Latif Y. Therapeutic 
role of coenzyme Q10 in brain injury during experimental diabetes. J Appl Pharm Sci 2013;3:213-7.

23. Jacobs NJ, Vandemark PJ. The purification and properties of the $\alpha$-glycerophosphate-oxidizing enzyme of Streptococcus faecalis 10C1. Arch Biochem Biophys 1960;88:250-5.

24. Allain CC, Poon LS, Chan CS, Richmond W, Fu PC. Enzymatic determination of total serum cholesterol. Clin Chem 1974;20:470-5.

25. Fruchart JC, Kora I, Cachera C, Clavey V, Duthilleul P, Moschetto Y. Simultaneous measurement of plasma apolipoproteins A-I and B by electro-immunoassay. Clin Chem 1982;28:59-62.

26. Friedewald WT, Levy RI, Fredrickso DS. Estimation of the concentration of low density lipoprotein cholesterol in plasma without use of preparative ultracentrifuge. Clin Chem 1972;18:499-502.

27. Pagalia DE, Valentine WN. Studies on the quantitative and qualitative characterization of erythrocyte glutathione peroxidase. J Lab Clin Med 1967;70:158-69

28. Nishikimi M, Roa NA, Yogi K. Measurement of superoxide dismutase. Biochem Biophys Res Common 1972;46:849-54

29. Ohkawa H, Ohishi N, Yagi K. Assay for lipid peroxides in animal tissues by thiobarbituric acid reaction. Anal Biochem 1979;95:351-8.

30. Kim M, Moon $\mathrm{H}$, Hong S. Determination of urinary 8-hydroxy-2- deoxyguanosine as a DNA damage marker. Am Clin Lab 2001;2001:42-5.

31. Hussein J, El-Khayat Z, Taha M, Morsy S, Drees E, Khateeb S. Insulin resistance and oxidative stress in diabetic rats treated with flaxseed oil. J Med Plant Res 2012;6:5499-506.

32. Larsen K. Creatinine assay by a reaction-kinetic principle. Clin Chim Acta 1972;41:209-17.

33. Drury RA, Wallington EA. Carleton's Histological Technique. $4^{\text {th }}$ ed. New York: Oxford University Press; 1980.

34. Armitage P, Berry G. Comparison of several groups. In: Statistical Methods in Medical Research. $2^{\text {nd }}$ ed. Oxford: Blackwell Scientific Pub; 1987. p. 186-2.

35. Octavia Y, Tocchetti CG, Gabrielson KL, Janssens S, Crijns HJ, Moens AL, et al. Doxorubicin-induced cardiomyopathy: From molecular mechanisms to therapeutic strategies. J Mol Cell Cardiol 2012;52:1213-25

36. Razmaraii N, Babaei H, Mohajjel Nayebi A, Assadnassab G, Ashrafi Helan J, Azarmi Y, et al. Cardioprotective effect of grape seed extract on chronic doxorubicin-induced cardiac toxicity in wistar rats. Adv Pharm Bull 2016;6:423-33.

37. Abdel-Sattar E, El-Gayed SH, Shehata I, Ashour OM, Nagy AA, Mohamadin AM. Antioxidant and cardioprotective activity of Stachys schimperi Vatke against doxorubicin-induced cardiotoxicity. Bull Fac Pharm Cairo Univ 2012;1:41-7.

38. Hussein J, El-Bana M, Refaat E, El-Naggar M. Synthesis of carvacrolbased nanoemulsion for treating neurodegenerative disorders in experimental diabetes. J Funct Foods 2017;37:441-8.

39. Rahmani AH, Aly SM, Ali H, Babiker AY, Srikar S, Khan AA. Therapeutic effects of date fruits (Phoenix dactylifera) in the prevention of diseases via modulation of anti-inflammatory, anti-oxidant and antitumor activity. Int J Clin Exp Med 2014;7:483-91.

40. Abdalla AN, Almaliki WH, Mukhtar MH, Anwar F, Shahid I, Menshawi SA, et al. Ameliorative influence of dietary dates on doxorubicin-induced cardiac toxicity. Pharmacol Pharm 2016;7:343-53.

41. Kumar MH, Gupta YK. Antioxidant property of Celastrus paniculatus willd.: A possible mechanism in enhancing cognition. Phytomedicine 2002;9:302-11.

42. Hamza A, Amin A, Daoud S. The protective effect of a purified extract of Withania somnifera against doxorubicin-induced cardiac toxicity in rats. Cell Biol Toxicol 2008;24:63-73.

43. QuanJun Y, GenJin Y, LiLi W, YongLong H, Yan H, Jie L, et al. Protective effects of dexrazoxane against doxorubicin-induced cardiotoxicity: A Metabolomic study. PLoS One 2017;12:e0169567.

44. El Arem A, Thouri A, Zekri M, Saafi EB, Ghrairi F, Zakhama A, et al. Nephroprotective effect of date fruit extract against dichloroacetic acid exposure in adult rats. Food Chem Toxicol 2014;65:177-84.

45. Daoud A, Ben Mefteh F, Mnafgui K, Turki M, Jmal S, Ben Amar R, et al. Cardiopreventive effect of ethanolic extract of date palm pollen against isoproterenol induced myocardial infarction in rats through the inhibition of the angiotensin-converting enzyme. Exp Toxicol Pathol 2017;69:656-65.

46. Dhana RM, Sarumathy K, Palani S, Sakthivel K. Phytochemical studies by GC-MS and cardioprotective effect of Grewia hirsuta (GH) on doxorubicin induced cardiotoxicity in albino rats. Int J Univ Pharm Life
Sci 2011;1:1-18.

47. Mansouri E, Jangaran A, Ashtari A. Protective effect of pravastatin on doxorubicin-induced hepatotoxicity. Bratisl Lek Listy 2017;118:273-7.

48. Varadharajan R, Rajalingam D, Palani S. GCMS/MS analysis and cardioprotective potential of Cucumis callosus on doxorubicin induced cardiotoxicity in rats. Int J Pharm Pharm Sci 2016;8:239-45.

49. Koti BC, Vishwanathswamy AH, Wagawade J, Thippeswamy AH. Cardioprotective effect of lipistat against doxorubicin induced myocardial toxicity in albino rats. Indian J Exp Biol 2009;47:41-6.

50. Koutinos G, Stathopoulos GP, Dontas I, Perrea-Kotsarelis D, Couris E, Karayannacos PE, et al. The effect of doxorubicin and its analogue mitoxantrone on cardiac muscle and on serum lipids: An experimental study. Anticancer Res 2002;22:815-20.

51. Alsaif M, Khan LK, Alhamdan AH, Alorf SM, Harfi SH, Abdulaziz MA, et al. Effect of dates and gahwa (Arabian coffee) supplementation on lipids in hyper-cholesterolemic hamsters. India J Pharm 2007;3:123-9.

52. Hasan NS, Amom ZH, Nor A, Arapoc DJ, Azlan A. The role of dates (Phoenix dactylifera) aqueous extract in improving the plasma lipid profiles of diet-induced hypercholesterolemic rabbits. Res J Biol Sci 2010;5:632-7.

53. Metwaly MS, Dkhil MA, Al-Quarishy S. Role of Phoenix dactylifera in ameliorating Eimeria papillata-induced hepatic injury in mice. J Med Plant Res 2012;6:3041-7.

54. Del Rio D, Stewart AJ, Pellegrini N. A review of recent studies on malondialdehyde as toxic molecule and biological marker of oxidative stress. Nutr Metab Cardiovasc Dis 2005:15:316-28.

55. Menna P, Minotti G, Salvatorelli E. In vitro modeling of the structureactivity determinants of anthracycline cardiotoxicity. Cell Biol Toxicol 2007;23:49-62.

56. Liu Z, Song XD, Xin Y, Wang XJ, Yu H, Bai YY, et al. Protective effect of chrysoeriol against doxorubicin-induced cardiotoxicity in vitro. Chin Med J (Engl) 2009;122:2652-6.

57. Chen CT, Wang ZH, Hsu CC, Lin HH, Chen JH. In vivo protective effects of diosgenin against doxorubicin-induced cardiotoxicity. Nutrients 2015;7:4938-54.

58. Saafi EB, El Arem A, Issaoui M, Hammami M, Achour L. Phenolic content and antioxidant activity of four date palm (Phoenix dactylifera $\mathrm{L}$.) fruit varieties grown in Tunisia. Int J Food Sci Technol 2009;44:2314-9.

59. El-Gazzar UB, El-Far AH, Hussein AA. The ameliorative effect of Phoenix dactylifera extract on CC14 hepatotoxicity in New Zealand rabbits. J Appl Sci Res 2009;5:1082-7.

60. Naskar S, Islam A, Mazumder UK, Saha P, Haldar PK, Gupta M. In vitro and in vivo antioxidant potential of hydromethanolic extract of Phoenix dactylifera fruits. J Sci Res 2010;2:144-57.

61. Feng Z, Hu W, Marnett LJ, Tang MS. Malondialdehyde, a major endogenous lipid peroxidation product, sensitizes human cells to UV- and BPDE-induced killing and mutagenesis through inhibition of nucleotide excision repair. Mutat Res 2006;601:125-36.

62. Abdel Hamid OI, Ahmed MG, Hassaneine HM, Rashed HE. Evaluation of the role of captopril on clozapine-induced cardiotoxicity and hematotoxicity in adult male albino rats. Toxicol Res Appl 2017;1:1-11.

63. Wu LL, Chiou CC, Chang PY, Wu JT. Urinary 8-OHdG: A marker of oxidative stress to DNA and a risk factor for cancer, atherosclerosis and diabetics. Clin Chim Acta 2004;339:1-9.

64. ValavanidisA, VlachogianniT,Fiotakis C.8-hydroxy-2'-deoxyguanosine (8-OHdG): A critical bio-marker of oxidative stress and carcinogenesis. J Environ Sci Health Carcinog Ecotoxicol Rev 2009;27:120-39.

65. El-Khayat Z, Rasheed W, Ramzy T, Hussein J, Agaiby M, Morsy S, et al. Protective effect of garlic oil against liver injury in experimental animals. J Med Plant Res 2010;4:2359-69.

66. Swift LP, Rephaeli A, Nudelman A, Phillips DR, Cutts SM. Doxorubicin-DNA adducts induce a non-topoisomerase II-mediated form of cell death. Cancer Res 2006;66:4863-71.

67. Coldwel KE, Cutts SM, Ognibene TJ, Henderson PT, Phillips DR. Detection of adriamycin-DNA adducts by accelerator mass spectrometry at clinically relevant Adriamycin concentrations. Nucleic Acids Res 2008;36:e100

68. Abd Elbaky NA, Ali AA, Ahmed RA. Cardioprotective effect of simvastatin on doxorubicin induced oxidative cardiotoxicity in rats. J Basic Appl Sci 2010;6:29-38.

69. Putri H, Nagadi S, Larasati YA, Wulandari N, Hermawan A, Nugroho AE. Cardioprotective and hepatoprotective effects of Citrus hystrix peels extract on rats model. Asian Pac J Trop Biomed 2013;3:371-5. 